\title{
Decision Support Systems and Artificial Intelligence in Supply Chain Risk Management
}

\author{
George Baryannis, Samir Dani, Sahar Validi, and Grigoris Antoniou
}

\begin{abstract}
This chapter considers the importance of decision support systems for supply chain risk management (SCRM). The first part provides an overview of the different operations research techniques and methodologies for decision making for managing risks, focusing on multiple-criteria decision analysis methods and mathematical programming. The second part is devoted to artificial intelligence (AI) techniques which have been applied in the SCRM domain to analyse data and make decisions regarding possible risks. These include Petri nets, multi-agent systems, automated reasoning and machine learning. The chapter concludes with a discussion of potential ways in which future decision support systems for SCRM can benefit from recent advances in AI research.
\end{abstract}

\section{Introduction}

Over the past two decades several events have significantly affected global supply chains and have brought the need for management of risks to the forefront. From the 9/11 terrorist attacks and the 2008 economic crisis, to the 2011 Japan earthquake and tsunami (Pettit et al. 2013) and Thailand floods (Chopra and Sodhi 2014), to more recent examples such as the decision in 2016 of the UK to withdraw from the European Union (Matthews 2017) or the KFC chicken supply crisis in early 2018 (Green 2018), global supply chains are disrupted by a multitude of strategic, environmental, financial or political causes. Risks are also becoming more common, as discussed by Snyder et al. (2016) and Behzadi et al. (2017), due to the increased vulnerability of supply chains that adopt lean management and just-in-time production and logistics and the decrease in vertical integration which increases supply chain complexity.

The aforementioned factors have continuously renewed the interest of practitioners and suppliers in research related to risks in supply chains. According to Ho et al. (2015), supply chain risk can be defined by as "the likelihood and impact of unexpected macro and/or micro-level events that adversely influence any part of a supply chain, leading to operational, tactical or strategic level failures or irregularities". Research in supply chain risk is inextricably linked to uncertainty, as the most common cause of risk is the uncertainty of possible outcomes caused by imperfect knowledge or unpredictable events. Addressing risk

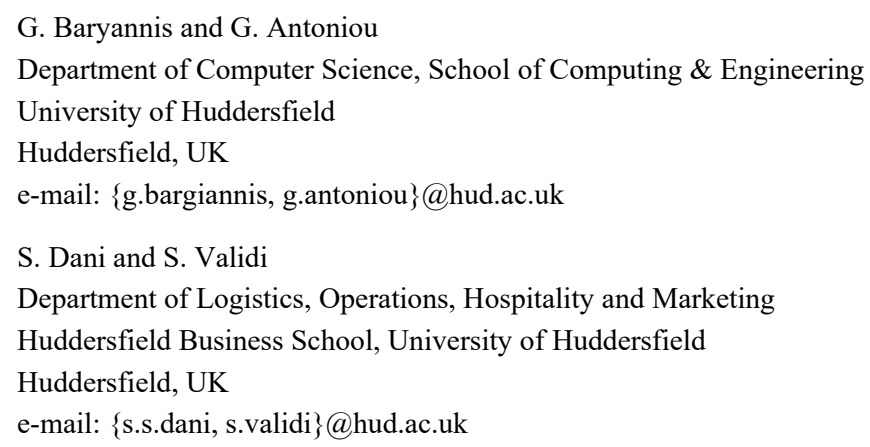


and uncertainty leads to reduced supply chain vulnerability, reduced impact of disruptions, while achieving higher degrees of robustness and resilience.

Supply chain risk management (SCRM) aims to provide a structured approach to achieve the aforementioned benefits. While there is no universally accepted definition, SCRM generally follows similar risk management strategies in other disciplines in that it consists of at least three phases: identification, assessment and mitigation (Ghadge et al. 2013). These phases depend on the coordination and collaboration of supply chain partners in order to make the correct decisions.

SCRM decision making reflects the complexity of the supply chain itself, involving the analysis of information from all involved parties and actions that affect anything from individual entities to the whole chain. To that end, operations and supply chain research communities have devoted significant effort in providing decision-makers with the support they need to achieve their SCRMrelated goals. This support ranges from methods and techniques that can be used to make more informed decisions to fully fledged decision support systems. Different techniques are utilised as per the phase in risk management. Some of the techniques employed for risk identification are supply chain vulnerability maps (Blos et al. 2009) and big data and process engineering approach (Wang et al. 2016). Ghadge et al. (2012) suggests that both qualitative and quantitative methods can be employed for risk assessment. Some of the quantitative techniques are supply chain network opportunity package (Brun et al. 2006), network analysis method to evaluate disruption propagation and its effect on supply chain network (T. Wu et al. 2007), Petri net (Mazzuto et al. 2012), data envelopment analysis and Monte Carlo simulation (D. D. Wu and Olson 2008) and fuzzy analytic hierarchy process (Samvedi et al. 2013). Risk mitigation as a process can employ both proactive and reactive strategies. Some of these strategies may include risksharing contracts (Ghadge et al. 2017), establishing strategic supplier relationships (Hajmohammad and Vachon 2015), encouraging suppliers' involvement (J. Chen et al. 2015), and reducing supply base complexity (Olson and Swenseth 2014).

The main purpose of this chapter is to summarise the various techniques that have been used to support decision making procedures within SCRM and investigate their capabilities, while also determining areas where there is untapped potential that can be leveraged to manage supply chain risks more effectively. Note that the analysis on SCRM research presented in this chapter is representative and by no means exhaustive. Interested readers can indicatively refer to the survey papers of Govindan et al. (2017) and Ho et al. (2015) for a comprehensive literature review of SCRM research.

The rest of this chapter is organised as follows. Section 2 focuses on multiplecriteria decision analysis methods and related techniques that try to find the best out of known solutions to a decision problem. Section 3 deals with methods that rely on mathematical programming to model the decision problem and find optimal solutions. Section 4 focuses on various other artificial intelligence (AI) techniques that have been exploited to support SCRM decision making, namely Petri nets, multi-agent systems, automated reasoning and machine learning. 
Finally, Section 5 concludes and suggests directions to further investigate the synergies between AI and SCRM to facilitate effective decision making.

\section{Multiple-criteria Decision Analysis for SCRM}

The problem of managing risks in supply chains is a prime example of a process relying on multiple-criteria decision analysis (MCDA) and decision-making (MCDM), since it entails evaluating the conflicting effects arising both from normal supply chain operation and due to associated risks. Hence, decision support systems for SCRM invariably rely on the vast array of MCDA techniques that have been proposed in literature. These techniques are usually grouped into two large categories: evaluation techniques, which find the best out of known alternative solutions, and design techniques, which represent the problem as a mathematical problem and solve it to find alternatives (which are initially unknown). In this section, the most prominent techniques belonging to the former category are outlined, along with related techniques that have been used to achieve the same goals, specifically decision trees, game theory and simulation. Section 3 focuses on the latter category, summarising mathematical programming techniques for SCRM.

\subsection{MCDA Methods}

Analytic Hierarchy Process (AHP) Introduced by Saaty (1980), AHP has become one of the most widely used tools for MCDM under uncertainty. The process involves three main steps: (1) the decision (goal) is decomposed into a hierarchy of alternatives and independent criteria (on one or more levels) that play a role in deciding among the alternatives; (2) a pairwise comparison is conducted between the goal and the criteria, as well as between alternatives and criteria, attributing priorities to all elements; and (3) the calculated priorities are checked for consistency and a decision is made. For instance, 17 different risk factors affecting a supply chain are manually identified in Schoenherr et al.(2008) and included as criteria in AHP in order to decide among five alternative choices for offshore suppliers of a manufacturing company.

Technique for Order of Preference by Similarity to Ideal Solution (TOPSIS) Proposed by Hwang and Yoon (1981), it relies on the notion of geometric distance to evaluate whether an alternative is better or worse. Alternatives and criteria are also pairwise compared like in AHP and weighted values are attributed to the pairs. Then, two imaginary solutions are constructed: the ideal solution, which has the highest value for all criteria and the negative ideal, which has the lowest value for all criteria. Finally, the geometric distances from these imaginary solutions are 
G. Baryannis et al.

Table 1. Comparison of MCDA evaluation methods that have been applied for SCRM

\begin{tabular}{|c|c|c|c|c|c|}
\hline Method & Description & Advantages & Disadvantages & SCRM task & Reference \\
\hline AHP & $\begin{array}{l}\text { Decomposes } \\
\text { decision into } \\
\text { hierarchy of } \\
\text { alternatives based } \\
\text { on criteria }\end{array}$ & $\begin{array}{l}\text { Supports both } \\
\text { qualitative and } \\
\text { quantitative } \\
\text { evaluation, group } \\
\text { decision making }\end{array}$ & $\begin{array}{l}\text { Problematic to } \\
\text { add/remove criteria } \\
\text { and alternatives, or } \\
\text { when some of these } \\
\text { are interdependent }\end{array}$ & $\begin{array}{l}\text { Assess, } \\
\text { Mitigate }\end{array}$ & $\begin{array}{l}\text { (Schoenherr } \\
\text { et al. 2008) }\end{array}$ \\
\hline TOPSIS & $\begin{array}{l}\text { Evaluates } \\
\text { alternatives based } \\
\text { on difference } \\
\text { from ideal } \\
\text { solution }\end{array}$ & $\begin{array}{l}\text { Simple and easy to } \\
\text { use, fixed number } \\
\text { of steps regardless } \\
\text { of number of } \\
\text { criteria }\end{array}$ & $\begin{array}{l}\text { Euclidean distance } \\
\text { calculation does not } \\
\text { consider correlation } \\
\text { among criteria }\end{array}$ & $\begin{array}{l}\text { Assess, } \\
\text { Mitigate }\end{array}$ & $\begin{array}{l}\text { (Samvedi et } \\
\text { al. 2013) }\end{array}$ \\
\hline DEA & $\begin{array}{l}\text { Maximises } \\
\text { efficiency of } \\
\text { alternatives by } \\
\text { calibrating input/ } \\
\text { output parameters }\end{array}$ & $\begin{array}{l}\text { Quantifies sources } \\
\text { of inefficiency for } \\
\text { alternatives }\end{array}$ & $\begin{array}{l}\text { Cannot measure } \\
\text { absolute efficiency }\end{array}$ & $\begin{array}{l}\text { Assess, } \\
\text { Mitigate }\end{array}$ & $\begin{array}{l}\text { (Azadeh and } \\
\text { Alem 2010) }\end{array}$ \\
\hline FMEA & $\begin{array}{l}\text { Identifies and } \\
\text { evaluates severity } \\
\text { and likelihood } \\
\text { of failures }\end{array}$ & $\begin{array}{l}\text { Directly applicable } \\
\text { to management of } \\
\text { risks }\end{array}$ & $\begin{array}{l}\text { Cannot consider } \\
\text { combination } \\
\text { of failures }\end{array}$ & $\begin{array}{l}\text { Identify, } \\
\text { Assess }\end{array}$ & $\begin{array}{l}\text { (P.-S. Chen } \\
\text { and Wu } \\
2013)\end{array}$ \\
\hline
\end{tabular}

calculated for all alternatives, ranking them according to relative closeness: the optimal alternative is the one that is closest to the ideal and farthest from the negative ideal. Samvedi et al. (2013) combines AHP and TOPSIS in order to create a risk index to determine the severity of risk at a given state of a supply chain. It is noted that the authors employ fuzzy variations of both techniques, where calculated priorities and weights are fuzzy numbers.

Data Envelopment Analysis (DEA) Charnes et al. (1978) introduced this evaluation method for alternative solutions that can be characterised by a set of inputs and a set of outputs. Each solution's efficiency score is the ratio of the weighted sums of outputs and inputs. Weights are calculated using mathematical optimisation, trying to maximise the efficiency of a solution, while making sure that all other efficiencies are reasonable (less than or equal to 1). Azadeh and Alem (2010) propose a decision making process for supplier selection under uncertainty that relies on fuzzy and stochastic variants of DEA. Input characteristics of suppliers (expected cost, quality acceptance level and on-time delivery distribution rate) and outputs are either modelled as triangular fuzzy numbers, or random variables, depending on whether available data is vague or uncertain.

Failure Mode and Effect Analysis (FMEA) While the aforementioned methodologies are generally applicable to any decision-making process, FMEA is designed to evaluate potential failures of a process and their impact, in order to be able to mitigate failure risk. Hence it is directly relevant to the goals of SCRM. The FMEA process involves several steps that identify possible failures and their 
causes, while also evaluating their severity and likelihood of occurring. Then, the current process is evaluated in terms of the likelihood of detecting these failures. Finally, failures are prioritised based on their severity, occurrence and detection likelihood and actions are recommended for each. P.-S. Chen and Wu (2013) approaches the supplier selection problem from the perspective of supply chain risk by combining AHP and FMEA. Several criteria for selecting suppliers are identified and FMEA is used to identify potential cases of suppliers failing to achieve high quality levels in terms of these criteria, evaluating whether these failures can be detected. Then, AHP is used to calculate weights for each criterion. Finally, failures are prioritised by calculating the product of their severity, occurrence, detection likelihood and AHP weight of the associated criterion.

Table 1 offers a summary and comparison of the aforementioned MCDA evaluation methods, outlining their advantages and disadvantages, the SCRM tasks they are typically used for and some key references.

\subsection{Related Techniques}

Simulation Many tasks within the SCRM process involve risk-related knowledge that may be unavailable and can be obtained in an exploratory manner. Simulation techniques have proven useful to that end and have been employed either on their own or combined with one of the methods analysed in this and subsequent sections. For instance, Kull and Closs (2008) uses discrete event simulation to assess the supply risk of an organisation and determine which factors contribute more to it. The work of Azadeh and Alem (2010) mentioned earlier uses the Monte Carlo method to simulate the linear models of the proposed DEA variants.

Decision Trees The inclusion of risks in an analysis of a supply chain leads to the need for representing several different alternative situations, depending on which aspects of the supply chain are affected. Decision trees are a suitable tool for such forms of representation and have been used in SCRM research mostly for risk analysis. For instance, Ruiz-Torres and Mahmoodi (2007) uses decision trees to determine the lowest cost approach under various supplier failure scenarios.

Game Theory Supply chains are a prime example of complex collaboration and competition among players, hence the related decision-making processes can also be modelled as a game, especially when these decisions involve economy-related risks. For example, Xiao and Yang (2008) applies game theoretic analysis for the case of rival supply chains to determine the effects of suppliers and retailers having different risk profiles (risk-neutral and risk-averse). 


\section{Mathematical Programming for SCRM}

Probably the most well-researched methodology to address risks in supply chains involves formalising supply chain interactions as a mathematical optimisation model which seeks to minimise one or more objective functions subject to a number of constraints. In contrast to most of the methodologies presented in Section 2, no alternative solutions are known beforehand; they can only be found by solving the models. There is a wide variation in terms of how these models address the inherent uncertainty in risks, as well as how they are solved. The rest of this section attempts to summarise approaches to address both of these aspects, focusing on stochastic programming, robust optimisation and fuzzy programming, in terms of handling uncertainty and exact, heuristic and metaheuristic algorithms in terms of model solving.

\subsection{Modelling Uncertainty}

Simple mathematical supply chain models include deterministic parameters that are assumed to be fully known. However, this is in contrast to the realities of supply chains where parameters may only partially known and may be subject to variation, especially due to various risks within or outside the supply chain network. Thus, some degree of uncertainty needs to be integrated in the model parameters. Three different ways have been proposed in literature to achieve this.

Stochastic Programming The most common solution is to introduce stochastic parameters for those aspects of the supply chain model that are uncertain, such as demand, supply, return, various aspects of cost and so on. These parameters may be continuous or discrete. In the former case, it is assumed they follow a distribution with known mean and variance, as is the case in the model of Miranda and Garrido (2008) or Taleizadeh et al. (2011), indicatively, where authors model daily demand as a random variable with a fixed mean and variance. Alternatively, uncertain parameters are modelled via a number of discrete scenarios whose occurrence probability is known. The most common case is the so-called twostage model, where some decisions are made regardless of the values of uncertain parameters (first stage), while the rest follow afterwards and depend on a finite number of realisations of these parameters. In Santoso et al. (2005), for instance, supply chain configuration decisions (e.g. processing centres placement) are fixed, while processing cost, demand, supply and capacity are all considered random variables with a finite number of possible realisations. Finally, a less common approach is to consider more than one periods for the second stage or, equivalently, more than two stages. For instance, Nickel et al. (2012), considers multiple periods after the first stage, each with its own possible scenarios, which essentially leads to a tree representation of all scenarios. 
Table 2. Comparison of mathematical programming approaching to modelling uncertainty

\begin{tabular}{|c|c|c|c|c|}
\hline Method & Description & Advantages & Disadvantages & Reference \\
\hline $\begin{array}{l}\text { Stochastic } \\
\text { Programming } \\
\text { (SP) }\end{array}$ & $\begin{array}{l}\text { Uses stochastic } \\
\text { variable with known } \\
\text { distributions to model } \\
\text { risk and uncertainty }\end{array}$ & $\begin{array}{l}\text { Granularity can be } \\
\text { adapted easily, } \\
\text { two-stage very } \\
\text { close to the supply } \\
\text { chain decision } \\
\text { making process }\end{array}$ & $\begin{array}{l}\text { Probability } \\
\text { distributions must be } \\
\text { known for parameters, } \\
\text { can become } \\
\text { exceptionally } \\
\text { complex }\end{array}$ & $\begin{array}{l}\text { (Miranda and } \\
\text { Garrido } \\
\text { 2008); } \\
\text { (Santoso et } \\
\text { al. 2005) }\end{array}$ \\
\hline $\begin{array}{l}\text { Robust } \\
\text { Optimisation } \\
\text { (RO) }\end{array}$ & $\begin{array}{l}\text { Determines solutions } \\
\text { that are nearly } \\
\text { optimal or nearly } \\
\text { feasible in any } \\
\text { realisation }\end{array}$ & $\begin{array}{l}\text { No probability } \\
\text { distributions } \\
\text { necessary, } \\
\text { generally less } \\
\text { complex than SP }\end{array}$ & $\begin{array}{l}\text { Delivers more } \\
\text { conservative (worst- } \\
\text { case) solutions than } \\
\text { SP or FP }\end{array}$ & $\begin{array}{l}\text { (Pishvaee et } \\
\text { al. 2011) }\end{array}$ \\
\hline $\begin{array}{l}\text { Fuzzy } \\
\text { Programming } \\
\text { (FP) }\end{array}$ & $\begin{array}{l}\text { Uses fuzzy numbers } \\
\text { to model risk and } \\
\text { uncertainty }\end{array}$ & $\begin{array}{l}\text { Models ambiguity } \\
\text { and vagueness, } \\
\text { generally more } \\
\text { tractable than SP }\end{array}$ & $\begin{array}{l}\text { Models are more } \\
\text { difficult to grasp, } \\
\text { requires more } \\
\text { expertise }\end{array}$ & $\begin{array}{l}\text { (Amid et al. } \\
\text { 2009); } \\
\text { (Torabi et al. } \\
\text { 2015) }\end{array}$ \\
\hline
\end{tabular}

Robust Optimisation If distributions of uncertain parameters are unknown, then the aforementioned solutions are not applicable. Instead, one can assume that parameters vary within a predefined interval or that they follow discrete scenarios for which, however, probabilities are unknown. In such a setting, robust optimisation techniques (Mulvey et al. 1995) can be applied to find an optimal solution across all possible realisations. Specifically, a solution is considered solution-robust if it remains close to optimal (e.g. it leads to a minimum increase of the optimal cost), while it is considered model-robust if it remains feasible (i.e. does not violate any constraints) for all possible realisations. A notable example is the work of Pishvaee et al. (2011), where the authors consider transportation costs, demand and return to be uncertain in a closed-loop supply chain network and assume that they vary within a prespecified bounded box. The optimisation objective is then to find solutions that satisfy the constraints for all possible realisations of these variables while keeping costs close to the optimal minimum.

Fuzzy Programming Instead of modelling uncertain parameters as stochastic variables, several works propose to treat them as fuzzy numbers corresponding to a set of possible values with weights attributed according to membership functions, while the corresponding constraints are modelled as fuzzy sets. This leads to so-called fuzzy possibilistic programming solutions that incorporate a level of flexibility in the possible parameter realisations. For instance, Amid et al. (2009) assumes that demand follows a triangular function, where the probability of possible demand values ranges from 0 at a lower and an upper limit, and peaks at 1 for a value in between. Also, net costs, quality and service levels follow an Rfunction, where there are two intervals, one corresponding to values of the highest probability, followed by a second one where probability decreases linearly, reaching zero for an upper limit value. On the other hand, Torabi et al. (2015) 
assumes discrete scenarios for demand, supply and cost, with parameter values for each scenario following triangular membership functions.

Table 2 offers a summary and comparison of the aforementioned modelling approaches. It should be noted that there are works which combine the aforementioned techniques into hybrid solutions. For instance, Bai and Liu (2016) models demand and cost as fuzzy numbers but incorporates a robustness element by using variable membership functions instead of fixed ones. Zhalechian et al. (2016) models some aspects of uncertainty using fuzzy numbers, while others are modelled using stochastic chance-constrained programming. Finally, Keyvanshokooh et al. (2016) proposes a hybrid robust-stochastic approach, where transportation costs are modelled through stochastic scenarios, while robust optimisation is applied for demand and return quantities which assume to take values from a finite set.

\subsection{Model Solving}

The above analysed mathematical programming techniques often result in very complex models that are not solvable directly. Stochastic continuous models are most often non-linear and are usually simplified through linearisation. Scenariobased stochastic models have to be converted to deterministic equivalents, where there is a separate set of constraints for each scenario, resulting in even larger models. Fuzzy models are also reformulated to their crisp (defuzzified) equivalents, interpreting membership degrees of fuzzy sets using real values. Then, depending again on the complexity of the resulting model, one of the solution approaches described in the rest of this section is followed.

Commercial Solvers In many cases, the resulting model is solvable using a proprietary optimisation software package in a reasonable amount of time. Modelling and optimisation systems commonly referenced in literature include $\mathrm{CPLEX}^{1}, \mathrm{GAMS}^{2}, \mathrm{LINGO}^{3}$ and GUROBI${ }^{4}$.

Optimal Solution Algorithms In other cases, well-known algorithms are employed, which have been proven capable of finding the optimal solution, provided that the model possesses specific characteristics. For instance, Santoso et al. (2005) applies Benders (or L-shaped) decomposition (Benders 1962) to solve the proposed model, relying on the fact that a two-stage stochastic program can be easily divided into sub-problems. A similar divide-and-conquer approach is followed in the Branch and Bound algorithm (Land and Doig 1960), which is

\footnotetext{
${ }^{1}$ https://www.ibm.com/analytics/data-science/prescriptive-analytics/cplex-optimizer

2 http://www.gams.com

${ }^{3} \mathrm{https} / / / \mathrm{www}$. lindo.com/index.php/products/lingo-and-optimization-modeling

${ }^{4}$ http://www.gurobi.com/products/gurobi-optimizer
} 
employed by Qi et al. (2010) in their attempt to investigate the effects of supply and demand disruptions on retailer location and customer allocation.

Heuristic Algorithms Model complexity may preclude finding an optimal solution, either because it requires unacceptable amounts of time or because the aforementioned algorithms fail to find such an exact solution. In such cases, heuristic algorithms are employed to find a good enough or an approximate solution. Probably the most common heuristic used in supply chain research is Lagrangian relaxation (LR) (Everett 1963) which uses multipliers to penalise violations of constraints and tries to minimise these values.

Metaheuristic Algorithms In other cases, standard heuristics are not able to find sufficiently good solutions, so a metaheuristic algorithm is employed to find or generate better heuristics. Many metaheuristics are inspired by nature, such as genetic algorithms (GA) which simulate the process of natural selection. Simulated annealing (SA) parallels the process of heating and slowly cooling materials in metallurgy with that of slowly decreasing the probability of accepting worse solutions while trying to find an optimal one. Peng et al. (2011) uses a GAbased metaheuristic for a model that attempts to reduce the risk of facility disruptions, while Lee and Dong (2009) address the typical problem of uncertain demand and return for reverse logistic networks using an SA-based algorithm to decide on facility locations and product flow. Other metaheuristics rely on local search methods, trying to improve on a candidate solution by slightly changing it. Cardona-Valdés et al. (2014) combine two such metaheuristics, GRASP and Tabu search, to address demand uncertainty in the decision-making process for warehouse location and transportation mode allocation.

\section{AI Techniques for SCRM}

The methods discussed in Section 2 focus primarily on integrating the opinions of stakeholders and partially automating the process of weighing the various criteria that factor in a decision. The mathematical programming techniques in Section 3 can broadly be considered as part of the AI field, since they apply intelligent methods of searching for a solution and are able to do so faster due to the constantly increasing computational capabilities of machines. However, the intelligence of such techniques is still constrained. This section explores other AI techniques that have received relatively little attention in supply chain research and discuss how these may prove useful to decision making for SCRM. 


\subsection{Petri Nets}

Viewed from a high level of abstraction, supply chains can be considered as discrete event dynamic systems, since their evolution is directly dependent on the occurrence of events over time. This is especially true when these events have significant effects to their operation, as is the case of risk events. The analysis of such systems usually relies on some kind of graph model, like Petri nets (Petri 1966). Petri nets consist of three types of elements: (1) places, modelling states, (2) transitions, modelling the transition from one place to another, and (3) arcs, connecting an initiating place to a transition and a transition to a subsequent place. Each place may have one or more tokens. For a transition to fire (i.e. occur), a predefined sufficient number of tokens must be present at the place leading to that transition.

Petri net models essentially represent cause and effect relationships which are fundamental in risk analysis. This has been recognised in SCRM literature by a handful of researchers. Asar et al. (2006) uses fault tree analysis to identify multiple levels of causes of disruption in a manufacturing supply chain, as well as existing mitigating techniques. The resulting fault tree is then converted to a Petri net, which is then used to determine the probability levels for each disruption and the success level of mitigation practices. Rossi and Pero (2012) follows a different approach, modelling the complete operation of a simple logistic network as a Petri net. Any product-related element is represented by a token (e.g. customer requests, occurred stock-outs, order quantities, safety stocks and so on). Risks are then identified by calculating the coverability graph of the Petri net, e.g. detecting cases where delivery lead times are higher than a threshold, or cases of inaccurate forecasts at the retailer or distributor side.

Zegordi and Davarzani (2012) uses a well-known variant called Coloured Petri nets which provide the ability to distinguish between tokens, using values called colours. These are employed to model the interconnected relationships among disruptions: each type of disruption is assigned a colour and when one disruption may cause another, a token is allowed to change colour. The graphs represent the supply chain operation as in Rossi and Pero (2012) and their analysis helps determine how disruptions propagate and how they affect performance.

\subsection{Multi-Agent Systems}

A supply chain involves a number of entities (customers, suppliers, and so on) interacting with each other, each with their own agendas, which may sometimes overlap or conflict. It is straightforward to imagine each one of these entities as an intelligent agent, model the supply chain as a multi-agent system (MAS) and use this system to support decision making. In such a MAS, each agent follows a set 
of rules that govern its interactions with the other agents. Agents communicate with each other by issuing requests and responses. In principle, after defining each agent's behaviour, a MAS can run independently and reach a solution without the need for human intervention, since agents are capable of perceiving their environment, respond to changes and initiate actions.

Kwon et al. (2007) proposes the use of MAS to address supply and demand uncertainties in manufacturing supply chain management. Three types of agents are modelled: retailers, manufacturers and suppliers. Each agent makes decisions according to the interests of the firm it represents and can adjust its behaviour to respond to risks. For instance, a manufacturer agent aims to maximise revenue and minimise costs, while it has to decide on order and production quantities and whether to expand its supplier base to address supply risk. The authors propose an iterative adjustment approach so that all agents achieve their profit goals, while the supply chain's profit is also maximised. Simulations are run with varying numbers for customer demand, lead time, production capacity and number of suppliers, while the manufacturer includes a risk pooling strategy in its behaviour to search for additional suppliers in the face of disruptions.

Mele et al. (2007) combine a MAS with Monte Carlo simulation and metaheuristics to retrofit a supply chain design due to uncertain demand, as well as transport and processing times. Specifically, a genetic algorithm is used to determine inventory control parameters. Then, different realisations of the uncertain parameters are obtained using Monte Carlo sampling. All parameter values are fed into the MAS which aims to maximise profit by emulations the decision-making process in terms of production scheduling, transport of materials and inventory replenishment. This process is iterated (applying genetic operators and generating new samples) until optimality criteria are met.

Giannakis and Louis (2011) present a holistic MAS framework for all phases of SCRM. Apart from agents representing supply chain entities, there are additional ones to support communication, coordination, monitoring, and disruption management. Risk identification relies on the monitoring agent detecting changes in performance indicators such as in-stock inventory, production throughput or delivery lead times. Assessment is then run by the disruption management agent, who investigates the root cause for each risk and determines risk impacts and probabilities. Then, past responses to each risk are collected in risk portfolios are evaluated, simulating their effects using the MAS. Finally, the best performing risk responses are proposed as solutions.

\subsection{Automated Rule-based Reasoning}

Decision-making for SCRM and supply chain management in general has always relied on the accumulated expertise and experience of key stakeholders. Automated reasoning systems provide a means of encoding this knowledge into a 
machine-interpretable form in order to (partially) automate the decision-making process. A common approach is to rely on a rule-based representation (with casebased being a popular alternative). Rules have the advantage of being easily interpretable by both humans and machines, since they follow a simple if-then formalisation

SCRIS (Kayis and Karningsih 2012) is a supply chain risk identification system that relies on rule-based knowledge encoded using the CLIPS ${ }^{5}$ language. The authors elicit knowledge from existing SCRM literature to collect supply chain risk events, factors and sub factors and their interrelations. These are expressed in the form of a rule hierarchy that facilitates a forward chaining inference approach: specific characteristics of a supply chain lead to the identification of risk sub factors, sub factors lead to factors, factors to events, and finally events to communication of identified risks. SCRIS is validated using several case studies, showing that it can identify $80 \%$ of potential risks.

Emmenegger et al. (2012) proposes an early warning system for procurement risks in supply chains that relies on information sources both internal to the supply chain and external (e.g. business information services or the Internet), which indicate the existence of a risk event. The system relies on an ontological risk model that includes enterprise semantics, risk events, risk indicators, warning signals and procurement risks. The ontology is written in $\mathrm{OWL}^{6}$ and rules are encoded in SQWRL (O'Connor and Das 2009), while the identification process is as follows. Risk events that are derived from information sources are aggregated and contribute to the calculation of risk indicators. If these exceed a threshold then a warning signal is issued. A particular risk is identified when all warning signals associated with it are issued.

\subsection{Machine Learning}

The past decade has seen a tremendous growth in research on and applications of machine learning, a research area within AI focusing on systems that are not only intelligent in the sense of deriving conclusions and making decisions but also due to their ability of learning in order to improve their performance. While machine learning principles have existed since the birth of $\mathrm{AI}$ as a research field (and even earlier, in the case of statistical methods), research has progressed rapidly in recent years, partly due to the increase in available computing power and the emergence of big data. While advances in machine learning have been exploited in various research areas, their application in SCRM has only been considered by few studies, which are analysed in the rest of this section.

\footnotetext{
${ }^{5}$ http://www.clipsrules.net

${ }^{6}$ https://www.w3.org/TR/owl2-overview
} 
The first study, to our knowledge, to incorporate machine learning in SCRMrelated tasks is that of Bruzzone and Orsoni (2003). The authors use Artificial Neural Networks (ANN), one of the earliest successes in machine learning research, to assess logistic performance risks in terms of actual transportation costs and production losses. ANNs are fed input data on production times, quantities and capacities. Then, they are trained using calculated cost estimates for the available input. This gives them the ability to learn to calculate cost estimates for different sets of input data. Evaluation results prove the superiority of ANNs in terms of flexibility, adaptability and accuracy of response, compared to discrete event simulation.

ANNs are combined with a case-based reasoning (CBR) system in Zhao and $\mathrm{Yu}$ (2011) to address the problem of supplier selection under uncertainty for the case of Chinese petroleum enterprises. CBR relies on the principle that if a solution was successful in the past, it may also successful in closely similar situations. The authors propose to use ANNs to improve on key problems of CBR: (1) how to objectively calculate suitable weights for all attributes that characterise a case; (2) how to determine the degree of similarity between existing cases and the target case; (3) how to extract rules from the cases; and (4) how to maintain the case base. ANNs are trained using existing cases, then use this knowledge to learn how to determine decisions for new cases, which are in turn expressed as new cases and stored in the case base to be used for future decisions.

The CBR approach is also adopted by Jiang and Sheng (2009) for the problem of inventory control under demand risk. Previous cases of replenishment actions using order-up-to levels or reorder points are collected, along with the achieved service levels. Then, a reinforcement learning approach is applied to make decisions for new cases, in terms of order-up-to levels or reorder points. The achieved service level is the actual reward (or punishment, if it is unsatisfactory) that helps the system learn which actions bring it closer to or further from the target service level. Results show that reinforcement learning achieves average service levels that are very close to the target level, especially in the case of reorder point replenishment.

M. Chen et al. (2010) propose the use of a Bayesian model for the management of manufacturing supply chains that face supply disruptions. This relies on Bayes' rule which relates the conditional probability of an event A happening given evidence $\mathrm{B}$, to the probability of A happening (in general), the probability of $\mathrm{B}$ being observed, and the probability of B being observed given that A happened. This allows re-calculating probabilities after new evidence is acquired. The authors' model assumes that disruptions affect supply in a number of fixed levels, each with an unknown probability. The goal of the model is to learn these probabilities over time, starting with initial values determined from past experience, expert assessment or provided by suppliers themselves. By learning these probabilities, the manufacturer can make informed decisions about sourcing strategies, even when the initial knowledge is imperfect. 
Table 3. Comparison of AI techniques that have been applied for SCRM

\begin{tabular}{|c|c|c|c|c|c|}
\hline Technique & Description & Advantages & Disadvantages & SCRM tasl & Reference \\
\hline Petri nets & $\begin{array}{l}\text { Model dynamic } \\
\text { systems in the } \\
\text { form of states } \\
\text { and transitions } \\
\text { between them }\end{array}$ & $\begin{array}{l}\text { Can be used at } \\
\text { various levels of } \\
\text { abstraction, } \\
\text { supports automatic } \\
\text { simulation }\end{array}$ & $\begin{array}{l}\text { May be difficult to } \\
\text { build, maintain and } \\
\text { interpret if network } \\
\text { too large }\end{array}$ & $\begin{array}{l}\text { Identify, } \\
\text { Assess }\end{array}$ & $\begin{array}{l}\text { (Asar et al. } \\
\text { 2006); } \\
\text { (Zegordi and } \\
\text { Davarzani } \\
2012)\end{array}$ \\
\hline $\begin{array}{l}\text { Multi-Agent } \\
\text { Systems }\end{array}$ & $\begin{array}{l}\text { Simulate } \\
\text { interactions } \\
\text { between entities } \\
\text { with predefined } \\
\text { behaviour }\end{array}$ & $\begin{array}{l}\text { Can rapidly react } \\
\text { and adapt to } \\
\text { changing } \\
\text { environments, } \\
\text { scales easily }\end{array}$ & $\begin{array}{l}\text { Formalising agent } \\
\text { behaviour requires } \\
\text { expertise and may } \\
\text { become too } \\
\text { complex }\end{array}$ & $\begin{array}{l}\text { Identify, } \\
\text { Assess, } \\
\text { Mitigate }\end{array}$ & $\begin{array}{l}\text { (Mele et al. } \\
2007) ; \\
\text { (Giannakis } \\
\text { and Louis } \\
\text { 2011) }\end{array}$ \\
\hline $\begin{array}{l}\text { Automated } \\
\text { Rule-based } \\
\text { Reasoning }\end{array}$ & $\begin{array}{l}\text { Encode } \\
\text { knowledge using } \\
\text { rules, infer } \\
\text { information and } \\
\text { choose actions }\end{array}$ & $\begin{array}{l}\text { Natural, intuitive } \\
\text { g way to encode } \\
\text { expert knowledge, } \\
\text { modular, powerful } \\
\text { reasoning systems }\end{array}$ & $\begin{array}{l}\text { Rules need to be } \\
\text { carefully crafted to } \\
\text { avoid loops or } \\
\text { contradictions, } \\
\text { may require large } \\
\text { rule sets }\end{array}$ & $\begin{array}{l}\text { Identify, } \\
\text { Assess, } \\
\text { Mitigate }\end{array}$ & $\begin{array}{l}\text { (Kayis and } \\
\text { Karningsih } \\
\text { 2012); } \\
\text { (Emmenegger } \\
\text { et al. 2012) }\end{array}$ \\
\hline $\begin{array}{l}\text { Machine } \\
\text { Learning }\end{array}$ & $\begin{array}{l}\text { Learn from } \\
\text { existing } \\
\text { knowledge and } \\
\text { make predictions } \\
\text { on previously } \\
\text { unknown setups }\end{array}$ & $\begin{array}{l}\text { Uncovers hidden } \\
\text { correlation in data, } \\
\text { continuously } \\
\text { simproves as more } \\
\text { data becomes } \\
\text { available }\end{array}$ & $\begin{array}{l}\text { Depends on the } \\
\text { availability of } \\
\text { relevant and } \\
\text { accurate datasets, } \\
\text { results may not be } \\
\text { interpretable }\end{array}$ & $\begin{array}{l}\text { Identify, } \\
\text { Assess, } \\
\text { Mitigate }\end{array}$ & $\begin{array}{l}\text { (P.-S. Chen } \\
\text { and Wu } \\
\text { 2013) }\end{array}$ \\
\hline
\end{tabular}

Bayes' rule is also featured in Garvey et al. (2015) in the form of Bayesian (Belief) Networks (BN). These graph models represent events that have a direct influence on others. Based on these connections, one can calculate the probability of an event taking place, given that others have also taken place. The authors model a set of risks as a $\mathrm{BN}$ and use it within the risk assessment process to determine how risk propagates. Each member of a supply network (distributors, manufacturers, retailers) is then evaluated in terms of their risk contribution factor and risk propagation ratio.

The work of Zage et al. (2013) is unique since it is the only published SCRM study, to the best of our knowledge, that combines a machine learning approach with an implementation that exploits big data. The authors focus on security risks in supply chains, specifically the problem of identifying deceptive practices in ecommerce. First, they use a graph-based representation of transactions to determine relationships that are characteristic of deception. Then, they use these characteristics as features in a clustering approach to distinguish legitimate users (those who do not exhibit such characteristics) and fraudsters. The algorithm relies on large-scale Web data, collecting information for vendors through their Web presence. Evaluation shows that high accuracy in detecting fraudsters is achieved even when the classifier is trained with only one-third of the available data. Table 3 provides a summary and comparison of all AI techniques presented in this Section. 


\section{Conclusions}

The wide variety of available methods and techniques presented in this chapter supports the fact that supply chain decision-makers nowadays have access to a powerful arsenal in their quest to manage risks that affect the supply chain. This gives them the ability to choose the tools that are most suitable to their goals. From our analysis, we can draw the following conclusions:

- MCDA analysis methods such as AHP, TOPSIS, DEA or FMEA are more suitable when the various alternative choices are known and the decision-maker needs a structured and systematic way of deciding among them. This makes them especially suitable for deciding among different risk mitigation plans.

- Mathematical modelling and optimisation excel at capturing the full spectrum of parameters, constraints and objectives that are involved in a supply chain decision and can provide optimal or close to optimal solutions for highly complex models. Thus, they are suited for the case when a supply chain can be modelled in detail, the target objectives are fully known, but the different ways of achieving these objectives are not completely known. In such cases, mathematical optimisation can derive risk mitigation decisions and plans that achieve SCRM-related objectives.

- AI techniques are very diverse, which means that their success depends on choosing the suitable technique for the task at hand. For instance, networkbased approaches like Petri nets are especially suitable when one needs to trace interactions and assess the dynamic behaviour of a supply chain. Multi-agent systems can place more focus on the conflicting or coordinating interactions among different supply chain stakeholders. Rule-based reasoning techniques are excellent when knowledge can be easily encoded in the form of rules. Finally, machine learning techniques can support a wide variety of tasks but can only do so effectively when an adequate amount of data is available.

Since each technique has its own set of capabilities and may be more suitable for some aspects of SCRM than others (as summarised in Tables 1, 2 and 3), it makes sense to explore the possibility of combining two or more of the presented methods and techniques into a comprehensive decision support system for SCRM. While some cases of hybridisation have been reported in literature (e.g. in the work of Keyvanshokooh et al. (2016)), they usually follow specific patterns, such as the introduction of fuzziness into existing techniques, or the combination of mathematical programming with MCDA analysis methods. However, it would also be interesting to explore a hybrid approach that integrates one of the AI techniques in Section 4 with the powerful optimisation abilities of mathematical programming.

Finally, what should be evident from the discussion in Section 4 is that, while research in AI techniques has made strides in recent years, SCRM and operations research in general, have not fully exploited the associated benefits. In particular, 
the powerful predictive and learning capabilities of machine learning and big data analytics have an indisputable potential that can revolutionise SCRM, both with regard to identifying and assessing risks more quickly and accurately and determining the optimal ways to respond to them in order to create more robust and resilient supply chains.

\section{References}

Amid, A., Ghodsypour, S. H., \& O'Brien, C. (2009). A weighted additive fuzzy multiobjective model for the supplier selection problem under price breaks in a supply Chain. International Journal of Production Economics, 121(2), 323-332, doi:10.1016/j.ijpe.2007.02.040.

Asar, A., Meng, C. Z., Caudill, R. J., \& Asar, S. (2006). Modelling risks in supply chains using Petri net approach. International Journal of Services Operations and Informatics, 1(3), 273-285, doi:10.1504/ijsoi.2006.011016.

Azadeh, A., \& Alem, S. M. (2010). A flexible deterministic, stochastic and fuzzy Data Envelopment Analysis approach for supply chain risk and vendor selection problem: Simulation analysis. Expert Systems with Applications, $\quad 37(12), \quad 7438-7448$, doi:https://doi.org/10.1016/j.eswa.2010.04.022.

Bai, X., \& Liu, Y. (2016). Robust optimization of supply chain network design in fuzzy decision system. Journal of Intelligent Manufacturing, 27(6), 1131-1149, doi:10.1007/s10845-014-0939-y.

Behzadi, G., O'Sullivan, M. J., Olsen, T. L., \& Zhang, A. (2017). Agribusiness supply chain risk management: A review of quantitative decision models. Omega (United Kingdom), doi:10.1016/j.omega.2017.07.005.

Benders, J. F. (1962). Partitioning procedures for solving mixed-variables programming problems. Numer. Math., 4(1), 238-252, doi:10.1007/bf01386316.

Blos, M. F., Quaddus, M., Wee, H. M., \& Watanabe, K. (2009). Supply chain risk management (SCRM): a case study on the automotive and electronic industries in Brazil. Supply Chain Management: An International Journal, 14(4), 247-252, doi:10.1108/13598540910970072.

Brun, A., Caridi, M., Fahmy Salama, K., \& Ravelli, I. (2006). Value and risk assessment of supply chain management improvement projects. International Journal of Production Economics, 99(1), 186-201, doi:https://doi.org/10.1016/j.ijpe.2004.12.016.

Bruzzone, A., \& Orsoni, A. (2003). AI and simulation-based techniques for the assessment of supply chain logistic performance. 2003-January, 154-164, doi:10.1109/simsym.2003.1192809. 
Cardona-Valdés, Y., Álvarez, A., \& Pacheco, J. (2014). Metaheuristic procedure for a bi-objective supply chain design problem with uncertainty. Transportation Research Part B: Methodological, 60, 66-84, doi:10.1016/j.trb.2013.11.010.

Charnes, A., Cooper, W. W., \& Rhodes, E. (1978). Measuring the efficiency of decision making units. European Journal of Operational Research, 2(6), 429-444, doi:https://doi.org/10.1016/0377-2217(78)90138-8.

Chen, J., Zhao, X., \& Shen, Z.-J. (2015). Risk Mitigation Benefit from Backup Suppliers in the Presence of the Horizontal Fairness Concern. Decision Sciences, 46(4), 663-696, doi:10.1111/deci.12157.

Chen, M., Xia, Y., \& Wang, X. (2010). Managing supply uncertainties through Bayesian information update. IEEE Transactions on Automation Science and Engineering, 7(1), 24-36, doi:10.1109/tase.2009.2018466.

Chen, P.-S., \& Wu, M.-T. (2013). A modified failure mode and effects analysis method for supplier selection problems in the supply chain risk environment: A case study. Computers \& Industrial Engineering, 66(4), 634-642, doi:https://doi.org/10.1016/j.cie.2013.09.018.

Chopra, S., \& Sodhi, M. S. (2014). Reducing the Risk of Supply Chain Disruptions. MIT Sloan Management Review(55), 73-80.

Emmenegger, S., Laurenzi, E., \& Thönssen, B. (2012). Improving supply-chainmanagement based on semantically enriched risk descriptions. 70-80.

Everett, H. (1963). Generalized Lagrange Multiplier Method for Solving Problems of Optimum Allocation of Resources. Oper. Res., 11(3), 399-417, doi:10.1287/opre.11.3.399.

Garvey, M. D., Carnovale, S., \& Yeniyurt, S. (2015). An analytical framework for supply network risk propagation: A Bayesian network approach. European Journal of Operational Research, 243(2), 618-627, doi:10.1016/j.ejor.2014.10.034.

Ghadge, A., Dani, S., Chester, M., \& Kalawsky, R. (2013). A systems approach for modelling supply chain risks. Supply Chain Management: An International Journal, 18(5), 523-538, doi:doi:10.1108/SCM-11-20120366.

Ghadge, A., Dani, S., \& Kalawsky, R. (2012). Supply chain risk management: Present and future scope. The International Journal of Logistics Management, 23(3), 313-339, doi:10.1108/09574091211289200.

Ghadge, A., Dani, S., Ojha, R., \& Caldwell, N. (2017). Using risk sharing contracts for supply chain risk mitigation: A buyer-supplier power and dependence perspective. Computers \& Industrial Engineering, 103, $262-$ 270, doi:https://doi.org/10.1016/j.cie.2016.11.034.

Giannakis, M., \& Louis, M. (2011). A multi-agent based framework for supply chain risk management. Journal of Purchasing and Supply Management, 17(1), 23-31, doi:10.1016/j.pursup.2010.05.001.

Govindan, K., Fattahi, M., \& Keyvanshokooh, E. (2017). Supply chain network design under uncertainty: A comprehensive review and future research 
directions. European Journal of Operational Research, 263(1), 108-141, doi:10.1016/j.ejor.2017.04.009.

Green, W. (2018). Five lessons from the KFC chicken crisis CIPS Supply Management.

Hajmohammad, S., \& Vachon, S. (2015). Mitigation, Avoidance, or Acceptance? Managing Supplier Sustainability Risk. Journal of Supply Chain Management, 52(2), 48-65, doi:10.1111/jscm.12099.

Ho, W., Zheng, T., Yildiz, H., \& Talluri, S. (2015). Supply chain risk management: A literature review. International Journal of Production Research, 53(16), 5031-5069, doi:10.1080/00207543.2015.1030467.

Hwang, C.-L., \& Yoon, K. (1981). Multiple attribute decision making (Lecture notes in economics and mathematical systems). Berlin: Springer.

Jiang, C., \& Sheng, Z. (2009). Case-based reinforcement learning for dynamic inventory control in a multi-agent supply-chain system. Expert Systems with Applications, $36(3$ Part 2), 6520-6526, doi:10.1016/j.eswa.2008.07.036.

Kayis, B., \& Karningsih, P. D. (2012). SCRIS: A knowledge-based system tool for assisting manufacturing organizations in identifying supply chain risks. Journal of Manufacturing Technology Management, 23(7), 834852, doi:10.1108/17410381211267682.

Keyvanshokooh, E., Ryan, S. M., \& Kabir, E. (2016). Hybrid robust and stochastic optimization for closed-loop supply chain network design using accelerated Benders decomposition. European Journal of Operational Research, 249(1), 76-92, doi:10.1016/j.ejor.2015.08.028.

Kull, T., \& Closs, D. (2008). The risk of second-tier supplier failures in serial supply chains: Implications for order policies and distributor autonomy. European Journal of Operational Research, 186(3), 1158-1174, doi:https://doi.org/10.1016/j.ejor.2007.02.028.

Kwon, O., Im, G. P., \& Lee, K. C. (2007). MACE-SCM: A multi-agent and casebased reasoning collaboration mechanism for supply chain management under supply and demand uncertainties. Expert Systems with Applications, 33(3), 690-705, doi:10.1016/j.eswa.2006.06.015.

Land, A. H., \& Doig, A. G. (1960). An Automatic Method of Solving Discrete Programming Problems. Econometrica, 28(3), 497-520, doi: $10.2307 / 1910129$.

Lee, D. H., \& Dong, M. (2009). Dynamic network design for reverse logistics operations under uncertainty. Transportation Research Part E: Logistics and Transportation Review, 45(1), 61-71, doi:10.1016/j.tre.2008.08.002.

Matthews, A. (2017). Brexit Impacts on Irish Agri-food Exports to the UK

Les incidences du Brexit sur les exportations irlandaises de produits agroalimentaires vers le Royaume-Uni

Auswirkungen des Brexits auf die Agrar- und Lebensmittelexporte Irlands in das Vereinigte Königreich. EuroChoices, 16(2), 26-32, doi:10.1111/1746$692 x .12160$. 
Mazzuto, G., Bevilacqua, M., \& Ciarapica, F. E. (2012). Supply chain modelling and managing, using timed coloured Petri nets: a case study. International Journal of Production Research, 50(16), 4718-4733, doi:10.1080/00207543.2011.639397.

Mele, F. D., Guillén, G., Espuña, A., \& Puigjaner, L. (2007). An agent-based approach for supply chain retrofitting under uncertainty. Computers and Chemical Engineering, 31(5-6), 722-735, doi:10.1016/j.compchemeng.2006.12.013.

Miranda, P. A., \& Garrido, R. A. (2008). Valid inequalities for Lagrangian relaxation in an inventory location problem with stochastic capacity. Transportation Research Part E: Logistics and Transportation Review, 44(1), 47-65, doi:10.1016/j.tre.2006.04.002.

Mulvey, J. M., Vanderbei, R. J., \& Zenios, S. A. (1995). Robust Optimization of Large-Scale Systems. Operations Research, 43(2), 264-281, doi:10.1287/opre.43.2.264.

Nickel, S., Saldanha-da-Gama, F., \& Ziegler, H. P. (2012). A multi-stage stochastic supply network design problem with financial decisions and risk management. Omega, 40(5), 511-524, doi:10.1016/j.omega.2011.09.006.

O'Connor, M., \& Das, A. (2009). SQWRL: a query language for OWL. Paper presented at the Proceedings of the 6th International Conference on OWL: Experiences and Directions - Volume 529, Chantilly, VA,

Olson, D. L., \& Swenseth, S. R. (2014). Trade-offs in Supply Chain System Risk Mitigation. Systems Research and Behavioral Science, 31(4), 565-579, doi:10.1002/sres.2299.

Peng, P., Snyder, L. V., Lim, A., \& Liu, Z. (2011). Reliable logistics networks design with facility disruptions. Transportation Research Part B: Methodological, 45(8), 1190-1211, doi:10.1016/j.trb.2011.05.022.

Petri, C. A. (1966). Communication with automata. Hamburg.

Pettit, T. J., Croxton, K. L., \& Fiksel, J. (2013). Ensuring Supply Chain Resilience: Development and Implementation of an Assessment Tool. Journal of Business Logistics, 34(1), 46-76, doi:10.1111/jbl.12009.

Pishvaee, M. S., Rabbani, M., \& Torabi, S. A. (2011). A robust optimization approach to closed-loop supply chain network design under uncertainty. Applied Mathematical Modelling, 35(2), 637-649, doi:10.1016/j.apm.2010.07.013.

Qi, L., Shen, Z. J. M., \& Snyder, L. V. (2010). The effect of supply disruptions on supply chain design decisions. Transportation Science, 44(2), 274-289, doi:10.1287/trsc. 1100.0320 .

Rossi, T., \& Pero, M. (2012). A formal method for analysing and assessing operational risk in supply chains. International Journal of Operational Research, 13(1), 90-109, doi:10.1504/ijor.2012.044029. 
Ruiz-Torres, A. J., \& Mahmoodi, F. (2007). The optimal number of suppliers considering the costs of individual supplier failures. Omega, 35(1), 104115, doi:https://doi.org/10.1016/j.omega.2005.04.005.

Saaty, T. L. (1980). The analytic hierarchy process: planning, priority setting, resources allocation. New York: McGraw, 281.

Samvedi, A., Jain, V., \& Chan, F. T. S. (2013). Quantifying risks in a supply chain through integration of fuzzy AHP and fuzzy TOPSIS. International Journal of Production Research, 51(8), 2433-2442, doi:10.1080/00207543.2012.741330.

Santoso, T., Ahmed, S., Goetschalckx, M., \& Shapiro, A. (2005). A stochastic programming approach for supply chain network design under uncertainty. European Journal of Operational Research, 167(1), 96-115, doi:10.1016/j.ejor.2004.01.046.

Schoenherr, T., Tummala, V. M. R., \& Harrison, T. P. (2008). Assessing supply chain risks with the analytic hierarchy process: Providing decision support for the offshoring decision by a US manufacturing company. Journal of Purchasing and Supply Management, 14(2), 100-111, doi:https://doi.org/10.1016/j.pursup.2008.01.008.

Snyder, L. V., Atan, Z., Peng, P., Rong, Y., Schmitt, A. J., \& Sinsoysal, B. (2016). OR/MS models for supply chain disruptions: A review. IIE Transactions (Institute of Industrial Engineers), 48(2), 89-109, doi:10.1080/0740817x.2015.1067735.

Taleizadeh, A. A., Niaki, S. T. A., \& Barzinpour, F. (2011). Multiple-buyer multiple-vendor multi-product multi-constraint supply chain problem with stochastic demand and variable lead-time: A harmony search algorithm. Applied Mathematics and Computation, 217(22), 9234-9253, doi:10.1016/j.amc.2011.04.001.

Torabi, S. A., Baghersad, M., \& Mansouri, S. A. (2015). Resilient supplier selection and order allocation under operational and disruption risks. Transportation Research Part E: Logistics and Transportation Review, 79, 22-48, doi:10.1016/j.tre.2015.03.005.

Wang, G., Gunasekaran, A., Ngai, E. W. T., \& Papadopoulos, T. (2016). Big data analytics in logistics and supply chain management: Certain investigations for research and applications. International Journal of Production Economics, $\quad 176, \quad 98-110$, doi:https://doi.org/10.1016/j.ijpe.2016.03.014.

Wu, D. D., \& Olson, D. L. (2008). Supply chain risk, simulation, and vendor selection. International Journal of Production Economics, 114(2), 646655, doi:10.1016/j.ijpe.2008.02.013.

Wu, T., Blackhurst, J., \& O'Grady, P. (2007). Methodology for supply chain disruption analysis. International Journal of Production Research, 45(7), 1665-1682, doi:10.1080/00207540500362138.

Xiao, T., \& Yang, D. (2008). Price and service competition of supply chains with risk-averse retailers under demand uncertainty. International Journal of 
Production Economics, 114(1), 187-200, doi:https://doi.org/10.1016/j.ijpe.2008.01.006.

Zage, D., Glass, K., \& Colbaugh, R. (2013). Improving supply chain security using big data. 254-259, doi:10.1109/isi.2013.6578830.

Zegordi, S. H., \& Davarzani, H. (2012). Developing a supply chain disruption analysis model: Application of colored Petri-nets. Expert Systems with Applications, 39(2), 2102-2111, doi:10.1016/j.eswa.2011.07.137.

Zhalechian, M., Tavakkoli-Moghaddam, R., Zahiri, B., \& Mohammadi, M. (2016). Sustainable design of a closed-loop location-routing-inventory supply chain network under mixed uncertainty. Transportation Research Part E: Logistics and Transportation Review, 89, 182-214, doi:10.1016/j.tre.2016.02.011.

Zhao, K., \& Yu, X. (2011). A case based reasoning approach on supplier selection in petroleum enterprises. Expert Systems with Applications, 38(6), 68396847, doi:10.1016/j.eswa.2010.12.055. 